\title{
Irrigation pumping stations according to the hydraulic and operational indicators of pumping units
}

\author{
Makhmudjon Mamajanov ${ }^{1}$, Bakhtiyor Uralov ${ }^{2 *}$, Marina $\mathrm{Li}^{2}$, Eshmatboy Qalqonov ${ }^{2}$, \\ Panji Nurmatov $^{3}$, and Abdulatif Gayur ${ }^{2}$ \\ ${ }^{1}$ Andijan Institute of Agriculture and Agricultural Technologies, Andijan, Uzbekistan \\ ${ }^{2}$ Tashkent Institute of Irrigation and Agricultural Mechanization Engineers, Tashkent, Uzbekistan \\ ${ }^{3}$ Samarkand State Architectural and Civil Engineering Institute, Samarkand, Uzbekistan
}

\begin{abstract}
The paper presents the conditions and the degree of reduction of water supply and pressure of pumping stations (PS) depending on the hydraulic resistance of the water-supply channels and structures of the PS and other various factors. And also, the results of studies of the hydraulic and operational modes of water-supplying machine channels and structures of irrigation pumping stations are presented. Analyzing the operating conditions of the pumping units, it was found that the reasons for the decrease in their operating parameters are the following: a) an increase in the hydraulic resistance of the suction line due to sediment deposition in the intake chamber, as well as due to siltation and clogging of the PS suction pipeline; b) an increase in hydraulic resistance due to the accumulation of air at elevated points of the pressure pipeline, in particular, on the crest of the siphon outlet of the PS; c) a decrease in the hydraulic efficiency of pumping units due to an increase in the surface roughness of the parts of the flow path, it due to the effect of solid abrasive particles entering through the suction line of the PS. Also, the work presents the results of complex laboratory and field studies to study the intensity of wear of the elements of the flow path of centrifugal and axial pumps. The alternating pulsating load leads to an increase in the force of interaction of the hydroabrasive flow with the surface of the chamber and increases its wear by $10 \%$, and also reduces the productivity of the pumping unit to $9 \%$.
\end{abstract}

\section{Introduction}

Carrying out research work to improve the methods for calculating the head loss in the channel bed and improve the technologies for preventing an increase in the pressure loss in the channels of open machine channels of pumping stations, taking into account the hydraulic resistance of the supply channels and structures of pumping stations, are considered one of the main tasks in channel hydraulics [1-5]. Providing the necessary water demand for irrigation of agricultural crops is considered one of the urgent tasks in the world. In the world, agricultural products are grown on an area of 4 billion 886.3 million

*Corresponding author: vohidov.oybek@bk.ru 
hectares, of which systems of irrigation pumping stations use 43.2 percent of the land for irrigation of crops. With the increase in the area of agricultural crops, to provide the necessary amount of water with its growing demand, ensuring the reliability of the culvert and the operation of pumping stations is of particular importance [6-8]. The most important element of these pumping stations (PS) are water supply and water supply machine channels and structures of pumping stations (PS), research and clarification of hydraulic processes, accurate determination of water supply and manometry pressure of PS, taking into account the hydraulic resistance of the machine channels and the technical and economic indicators of which in many respects determine the reliability, durability, and efficiency of pumping stations of irrigation, industrial and agricultural enterprises. In this regard, there is a need to increase the efficiency of pumping stations (PS) operation by developing specific measures to reduce the hydraulic resistance of water supply and water supply machine channels, by improving the hydraulic characteristics of water intake structures of pumping stations (PS), and with the best organization of metering water supply and gauge pressure of pumping stations [9-13]. With the development of a complex of such measures, it is possible to ensure the economy of water, energy, and material resources.

\section{Method}

Full-scale and laboratory studies were carried out depending on the hydraulic resistance of the water-supply channels and structures of the PS. Based on the theory of vane hydraulic machines, a calculation method and a method for determining the water supply and pressure of pumping units are proposed. In carrying out experimental and field studies, the generally accepted standard methods of laboratory-bench tests of pumps were used according to the recommendations of the International Energy Commission (IEC).

\section{Results and Discussion}

To assess the impact of hydraulic processes occurring in the water supply and water supply structures, and hydromechanical processes occurring inside the pump, to reduce its water supply, units 1 and 2 of the PS "Turakurgan-1" and units 6 and 7 of the PS "Irrigator" (Namangan region, Uzbekistan) equipped with the same D4000-95 centrifugal pumps (22NDs with $n=730 \mathrm{rpm}$. Measurements and calculations of the main technical indicators of the pumps were carried out based on the existing standard research methodology $[1,2,11,14]$.

To determine the pump head, exemplary vacuum gauges and manometers were used, connected respectively to the suction and discharge nozzles, the water supply was determined by the value of the flow rate in the pipeline, which was measured using a Pitot tube, the shaft power was calculated by the formula based on the readings of the voltmeter and ammeter, the rotation frequency the shaft was measured using a tachometer. The head loss of the suction pipeline was determined according to the readings of two vacuum gauges installed: the first - in the initial section after turning the axis of the pipeline, the second - in the inlet pipe of the pump. The head loss of the suction line was calculated using the formula:

$$
h_{w}=h_{v a c}-h_{s}-\frac{V^{2}}{2 g}
$$


where, $h_{v a c}$ are readings of vacuum gauges № 1 or № $2 ; h_{s}$ are geodetic heights from the tail water level to vacuum connection; $V$ is flow rate at the pressure measuring point.

The resistance coefficient of the suction pipe is determined by the following expression:

$$
\zeta=\frac{2 g^{*} h_{w}}{V^{2}}
$$

Figure 1 shows a comparison of the factory characteristics with the unit № 1 of the PS "Turakurgan-I" data of field tests. As can be seen from Figure 1, the test points are slightly lower from the pressure line of the factory characteristic, but the pump consumes sufficient power. With a fully open valve, the pump head is $H_{B}=54.8 \mathrm{~m}$, the water supply was $Q_{B}=698 \mathrm{l} / \mathrm{s}$ instead of the design $Q_{A}=1000 \mathrm{l} / \mathrm{s}$, i.e., operating point $A$ shifted to point $B$, and the difference was $\Delta Q=302 \mathrm{l} / \mathrm{s}$. Due to the decrease in water supply, the pump's efficiency was $12-15 \%$ lower [14-19].

Analyzing the operating conditions of the pumping units, it was found that the reasons for the decrease in their operating parameters are the following:

a) an increase in the hydraulic resistance of the suction line due to sediment deposition in the water intake chamber, as well as due to siltation and clogging of the suction pipeline;

b) increase in hydraulic resistance due to the accumulation of air at elevated points of the pressure pipeline, in particular on the crest of the siphon outlet;

v) decrease in the hydraulic efficiency of the pump due to an increase in the surface roughness of the parts of its flow path due to the effect of solid abrasive particles;

g) a decrease in the volumetric efficiency of the pump due to an increase in the size of the clearances in the impeller seals due to the effect of hydroabrasive flow;

d) a decrease in the pump's volumetric efficiency due to an increase in the gap between the "tongue" of the spiral diverter and the impeller from the action of solid particles.

This means that the displacement of the design operating point "A" to the actual operating point " $B$ " in figure 1 depends on many factors; the degree of their influence on the reduction of water supply and pressure can be established by conducting a detailed analysis of all technical indicators of the pump, suction and pressure pipelines of the pumping unit [20-24].

Figure 2 shows the dependence of the resistance coefficient on the water supply of the pump with a dirty water intake chamber and after its partial flushing. Partial washing of sediment deposits in the chamber was achieved by increasing the bottom flow rates, forming a gap by covering its upper part with wooden shields. As can be seen from figure 2 , the coefficient of hydraulic resistance of the suction pipeline $\zeta$ decreases in all operating modes of the pump after partial flushing of the water intake chamber. As a result of a decrease in hydraulic resistance, the pump flow increased from $Q_{v}=698 \mathrm{l} / \mathrm{s}$ before $Q_{c}=738 \mathrm{l} / \mathrm{s}$, i.e., $q_{k}=40 \mathrm{l} / \mathrm{s}$ (see figure 1 ).

After flushing the chamber between the hydrodynamic curve $H_{t r}^{\prime \prime}=f(Q)$ and design curve $H_{t r}=f(Q)$ there was also a significant difference, i.e., the difference in pressure between points " $C$ " and " $E$ " has a significant value, which confirms the increased values of the pressure loss in the pipelines. To determine the actual values of the pressure loss in the pipelines, we used the readings of two vacuum gauges installed in the initial and final sections of the pumping unit. Multiple measurements of the vacuum values in the suction pipelines of the 1 st and 2 nd units were made. According to the measurement data, the head loss between the sections of measuring the pressure of the suction pipelines was calculated, which amounted to $h_{\text {suction }}^{\prime}=2.9 \ldots 3.5 \mathrm{~m}$, and according to the calculation 
should be $h_{v s}=0.53 \mathrm{~m}$ (head difference $H_{c}-H_{E}=h_{v s}^{\prime}$ in Figure 1). $\eta, \%$

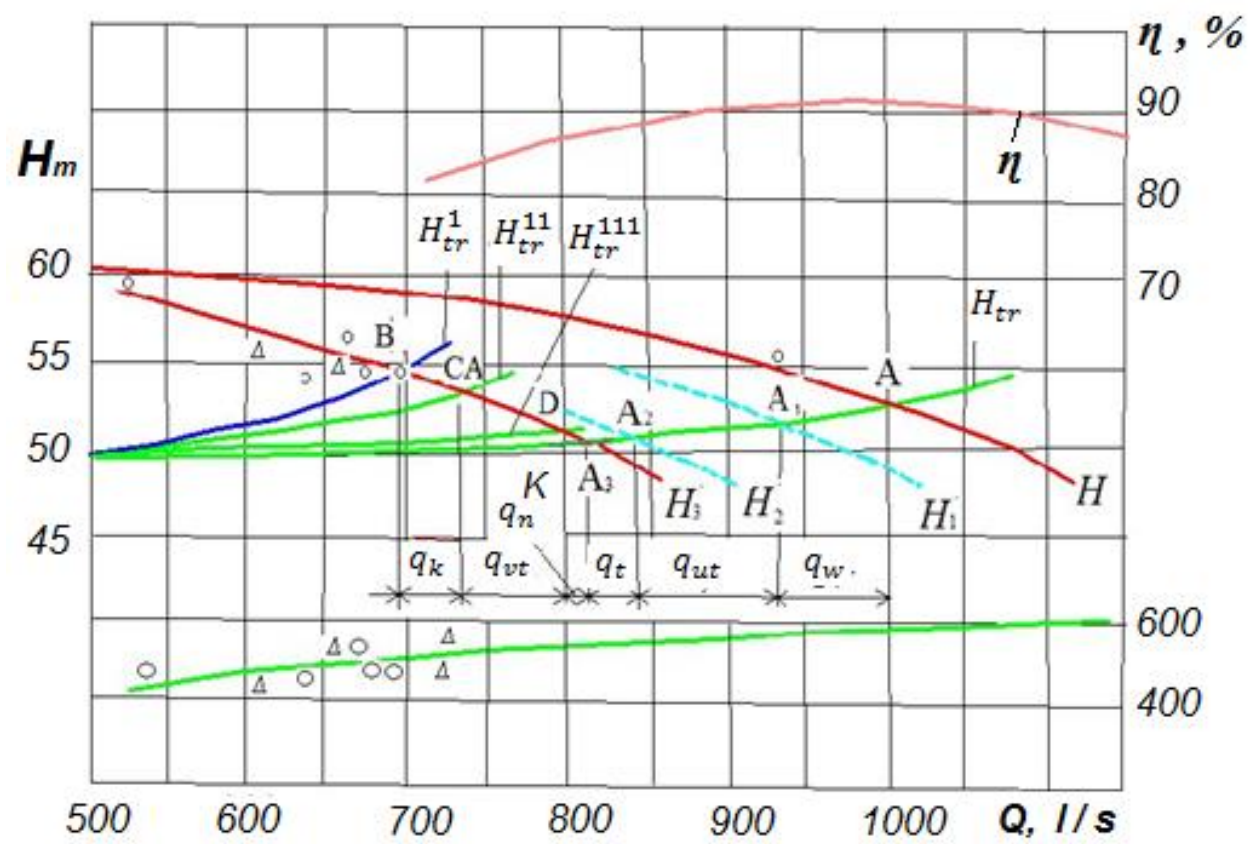

Fig. 1. Comparison of the design operating mode of the pump D4000-95 (22NDs) with the data of field tests $(\mathrm{n}=730 \mathrm{rpm}): H, N, \dot{\eta}$ are curves of pressure, power and efficiency according to the factory characteristic, $H_{t r}, H_{t r}^{1}, H_{t r}^{11}, H_{t r}^{111}$ are hydrodynamic curves, $A$ is design operating point, $B$ and $\mathrm{C}$ are respectively operating points before and after flushing the water intake chamber (according to field tests), $A_{1}, A_{2}, A_{3}$, D are predicted operating points.

Received values $h_{v s}^{\prime}$ and $h_{v s}$ show that cleaning of the suction line is required, and thus it is possible to increase the pump flow to $Q_{D}=800 \mathrm{l} / \mathrm{s}$ (that is still on $q_{v t}=62 \mathrm{l} / \mathrm{s}$ ).

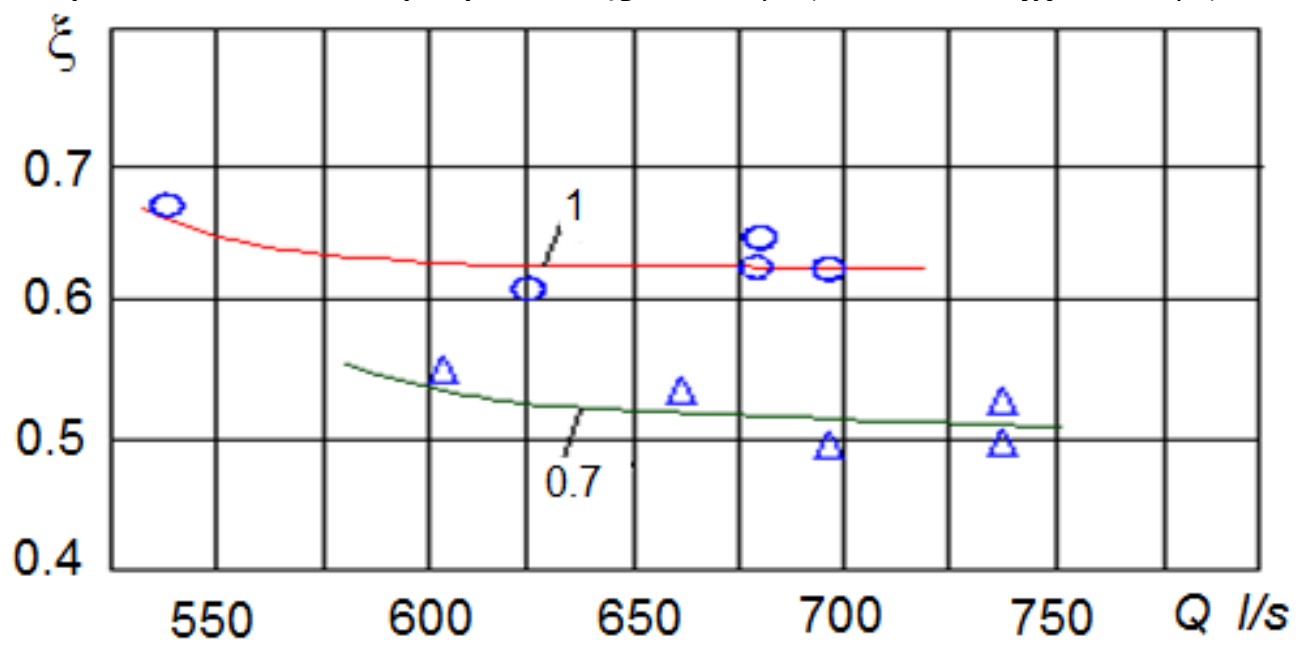

Fig. 2. Dependences of the resistance coefficient of the suction pipeline on the water supply of the centrifugal pump: 1-2 are, respectively, the curves obtained before and after flushing the water intake chamber of the pumping unit. 


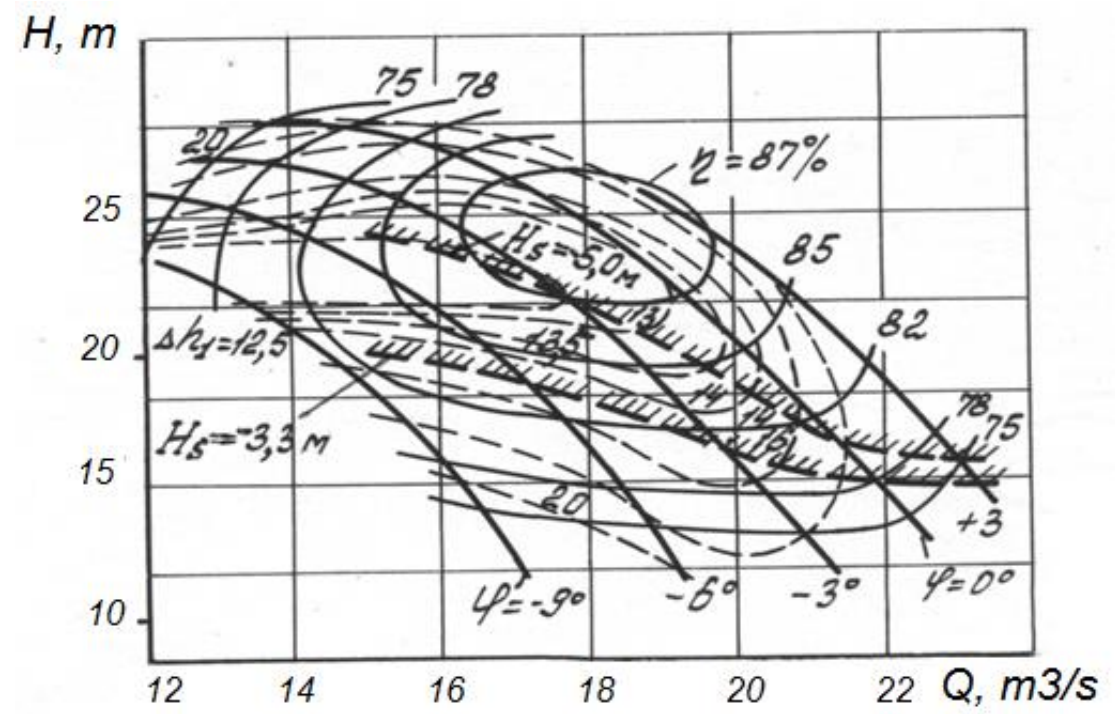

Fig. 3. Universal characteristic of the OP10-185 pump with isolines of the beginning of crevice cavitation and hydroabrasive wear

For reliability and comparison of the obtained data, similar experiments were carried out on a similar PS "Irrigator", which has the same brands of pumps D4000-95 (n= $730 \mathrm{rpm}$ ) and the same technical characteristics as the PS "Turakurgan-I". According to the studies of units № 6 and 7 of the PS "Irrigator", it was found that the values of the pressure loss found from the readings of two vacuum gauges and calculated by calculation were the same, i.e., its average value is $h_{v s}=0.47 \mathrm{~m}$, and the water supply of the pumps was $Q=825 \mathrm{l} / \mathrm{s}$. Let's compare the obtained values of $Q$ with the water supply of the pump of the station "Turakurgan-I", shown in figure 1. It corresponds to the regime point $\mathrm{A}_{3}$, since at this station there is no siltation of the water intake and the suction pipeline of the pumping unit.

According to the pressure gauge readings installed on the discharge pipe of the pump, the actual values of the pressure loss of the discharge line were found, and this value was verified by calculation. The difference between the calculated and the actual value of the pressure loss is $\Delta h_{n}=0.85 \mathrm{~m}$ (the difference in pressure between points $\mathrm{D}$ and $\mathrm{K}$ in figure 1), which was associated with the accumulation of air at the elevated points of the pressure pipeline. This means that with the removal of air from individual sections of the pressure pipeline, it is possible to increase the pump flow to $Q_{\mathrm{A} 3}=815 \mathrm{l} / \mathrm{s}$ (i.e., by another $\left.q_{n t}=15 \mathrm{l} / \mathrm{s}\right)$.

To determine the reasons for the decrease in water supply and pump pressure associated with hydromechanical processes occurring inside the pump, it is necessary to consider the change in the pump characteristics in the section between points $\mathrm{A}$ and $\mathrm{A}_{3}$ according to the hydrodynamic curve $H_{t r}=f(Q)$ (see figure 1). During long-term operation (more than 15 years), the surfaces of the flow path of the pump are exposed to solid abrasive particles present in the pumped water and have a scaly wavy shape, which leads to an increase in friction head loss. The end part of the blade working surface along the length $l=0.3 l_{\text {lop }}$, but it is restored annually. The pump inlets and outlets are slightly worn and have a smoother surface. The most uneven and scaly, wavy wear was on the surface of the pump spiral discharge device. Carrying out calculations according to the appropriate method [5$12]$, the total value of the pressure loss of the flowing part of the pump $h_{\text {nas }}=3.23 \mathrm{~m}$ was determined the head of the flowing part $h_{\text {nas }}=3.23 \mathrm{~m}$. Accordingly, the decrease in water supply due to the increase in the hydraulic resistance of the flowing part of the pump 
is $q_{w}=Q_{\mathrm{A}}-Q_{A 1}=1000-935=65 \mathrm{l} / \mathrm{s}$.

Suppose the initial clearance between the impeller disk and the sealing ring was $S_{o}=0.7 \mathrm{~mm}$, then at the time of testing, it was $S=2.72 \mathrm{~mm}$. According to the method described in $[12,15,17,24]$, calculations show that the increase in water leakage through the sealing gaps on both sides of the impeller will be equal to $q_{y}=90 \mathrm{l} / \mathrm{s}$.

Deferring the $q_{y}$ value from point $\mathrm{A}_{1}$ to the pump characteristic (see figure 1), we find point A2. As you can see, there is a difference between points $\mathrm{A}_{2}$ and $\mathrm{A}_{3}, q_{w}=30 \mathrm{l} / \mathrm{s}$, which means an increase in the amount of water leakage through the gap between the "tongue" of the diverting device and the impeller, as well as in the stuffing box. The permissible size of the gap in the "tongue" area must be $S_{t}=(0.03 \ldots 0.05) D_{2}=0.05$. $860=43 \mathrm{~mm}$. During long-term operation (more than 15 years), the actual value of the gap in the "tongue" area increased to $S_{t}=78 \mathrm{~mm}$, which is the reason for the increase in reverse leakage through this gap. Based on the above analysis, it is possible to compare certain reasons that affect the degree of decrease in water supply and pump pressure (Table $1)$.

To reduce the hydraulic resistance of the flow path, to reduce the value of $q_{w}$, it is necessary to treat the surfaces of the parts to clean and eliminate the roughness of the blade and the inner surface of the walls of the spiral diverter or to replace the pump casing, which is difficult to do under operating conditions, since this requires a lot. As shown in Table 1, an increase in the hydraulic resistance of the suction line $\left(q_{k}+q_{v . t .}=10.2 \%\right.$ and an increase in the gaps in the seals and the area of the "tongue" $\left.q_{t}+q_{w}=12 \%\right)$.

Table 1. The degree of reduction of water supply and pressure of the pump D4000-95, depending on various factors

\begin{tabular}{|l|c|c|c|c|}
\hline \multicolumn{1}{|c|}{ Name of quantities } & Designation & $\begin{array}{c}\text { Unit of } \\
\text { measurement }\end{array}$ & number & $\begin{array}{c}\text { Reduction of } \\
\text { water supply } \\
\text { and pump } \\
\text { head, } \%\end{array}$ \\
\hline $\begin{array}{l}\text { Decrease in water supply and } \\
\text { pressure due to siltation of the } \\
\text { water intake chamber. }\end{array}$ & $q_{k}$ & $1 / \mathrm{s}$ & 40 & 4 \\
\hline $\begin{array}{l}\text { Decrease in water supply and } \\
\text { pressure due to an increase in the } \\
\text { hydraulic resistance of the } \\
\text { suction pipeline. }\end{array}$ & $q_{v t}$ & $1 / \mathrm{s}$ & 62 & 6.2 \\
\hline $\begin{array}{l}\text { Decrease in water supply and } \\
\text { pressure due to an increase in the } \\
\text { hydraulic resistance of the } \\
\text { pressure pipeline. }\end{array}$ & $q_{n}$ & $1 / \mathrm{s}$ & 15 & 1.5 \\
\hline $\begin{array}{l}\text { Decrease in water supply and } \\
\text { pressure due to an increase in the } \\
\text { gap in the "tongue" area. }\end{array}$ & $q_{t}$ & $1 / \mathrm{s}$ & 30 & 3 \\
\hline $\begin{array}{l}\text { Decrease in water supply and } \\
\text { pressure due to an increase in the } \\
\text { sealing gap of the impeller. }\end{array}$ & $q_{u t}$ & $1 / \mathrm{s}$ & 90 & 9 \\
\hline $\begin{array}{l}\text { Reduction of water supply and } \\
\text { pressure due to an increase in the } \\
\text { hydraulic resistance of the pump } \\
\text { flow path. }\end{array}$ & $q_{w}$ & $1 / \mathrm{s}$ & 65 & 6.5 \\
\hline $\begin{array}{l}\text { The total value of the decrease in } \\
\text { water supply and pump head. }\end{array}$ & $\Delta Q$ & $1 / \mathrm{s}$ & 302 & 30.2 \\
\hline
\end{tabular}

It should be noted that, depending on the operating conditions of the pumping station, the 
percentages of reducing the water supply and pump head under the influence of individual factors may be different. For example, for the PS "Irrigator", there were no increases in the hydraulic resistances of the intake, suction, and discharge pipelines, and the sum of the values $q_{k}+q_{v . t}+q_{n . t}=0$. At this station, the decrease in water supply and pressure was associated only with hydromechanical processes taking place inside the pump, i.e., due to wear of the working parts of the pumping unit.

\section{Conclusions}

1. Based on the above analysis, it follows that it is required to develop a set of specific measures to improve the design of water supply channels and water intake structures of pumping stations (taking into account their hydraulic resistance), as well as to reduce wear of parts of the flow path and sealing elements of the impeller of the pumping unit.

2. The volumes of siltation of water-supply canals, water intake structures, and water intake chambers for individual PS are from 20 to 55\%, which leads to an increase in hydraulic resistance of the pump suction lines, and in some cases, to the formation of air funnels in the water intake chambers. Due to the increase in hydraulic resistance of the suction lines, the water supply of the D4000-95 pumps decreased to $10 \%$. Therefore, it is necessary to improve the design of water supply channels and water intake chambers of the PS operating at water sources with a high sediment content.

3. As a result of siltation of the water intake chambers, as well as an increase in the roughness of the surfaces of parts and the size of the sealing gap of the impeller due to hydroabrasive wear, the efficiency of the D4000-95 pumps was $12-15 \%$ lower than the design one.

4. From the above analysis, it follows that more intensive wear of the chamber than the end part of the impeller blades of an axial pump (Figure 3). However, the outflow rate of the hydroabrasive flow relative to the chamber will be much less than relative to the end part of the pump blade. The variable pulsating load leads to an increase in the force of interaction of the hydroabrasive flow with the surface of the chamber and increases its wear by 1.1 times, and also reduces the productivity of the pumping unit to $9 \%$.

\section{References}

1. Mamajonov, M., Bazarov, D. R., Uralov, B. R., Djumabaeva, G. U. \& Rahmatov, N. The impact of hydro-wear parts of pumps for operational efficiency of the pumping station. in Journal of Physics: Conference Series vol. 1425 (Institute of Physics Publishing, 2020).

2. Mamajanov, M. et al. Vane pumps with cavitation-abrasive wear of their parts. IOP Conf. Ser. Mater. Sci. Eng. 883, 012002 (2020).

3. Bazarov, D., Vatin, N., Bakhtiyor, O. \& Oybek, V. Hydrodynamic effects of the flow on the slab of the stand in the presence of cavitation. IOP Conf. Ser. Mater. Sci. Eng. 1030, 012110 (2021).

4. Bazarov, D. et al. The effects of morphometric elements of the channel on hydraulic resistance of machine channels of pumping stations. in IOP Conference Series: Materials Science and Engineering vol. 869 (Institute of Physics Publishing, 2020).

5. Bazarov, D., Markova, I., Raimova, I. \& Sultanov, S. Water flow motion in the vehicle of main channels. IOP Conf. Ser. Mater. Sci. Eng. 883, 012001 (2020).

6. Abduramanov A.A., Abduramanov Ye.A., K. M. I. Vyvod formuly gidroabrazivnogo iznosa lopatok rabochego kolesa tsentrobezhnogo nasosa. Nauk. i Obraz. Yuzhnogo Kazakhstana 37, 10-12 (2004). 
7. Abduramanov A.A., A. Y. A. K teorii dvizheniya zhidkosti rabochem kolese tsentrobezhnogo nasosa. Vestn. TarGU im. M.KH. Dulati 2, 41-46 (2004).

8. Bal'zannikov M.I., S. V. A. O snizhenii pul'satsii gidrodinamicheskogo davleniya v protochnoy chasti osevogo nasosa. Mater. 48-y nauchno-tekhn. konf. 38-41 (1991).

9. Dilshod, B., Markova, I., Sultanov, S. \& Kattakulov, F. Dynamics of the hydraulic and alluvial regime of the lower reaches of the Amudarya after the commissioning of the Takhiatash and Tuyamuyun hydrosystems. IOP Conf. Ser. Mater. Sci. Eng. 1030, 012110 (2021).

10. Eshev, S. et al. Non-eroding speed of water flow of channels running in cohesive soils. IOP Conf. Ser. Mater. Sci. Eng. 1030, 012131 (2021).

11. Ikramov, N., Majidov, T., Kan, E. \& Akhunov, D. The height of the pumping unit suction pipe inlet relative to the riverbed bottom. IOP Conf. Ser. Mater. Sci. Eng. 1030, 012125 (2021).

12. Kan, E., Muratov, A., Yusupov, M. \& Ikramov, N. Calculation of water hammer on the pressure pipeline of modernized irrigation pumping station. IOP Conf. Ser. Mater. Sci. Eng. 1030, 012127 (2021).

13. Obidov, B. et al. Hydrodynamic effects on the flow elements of the downstream devices in the presence of cavitation. IOP Conf. Ser. Mater. Sci. Eng. 1030, 012114 (2021).

14. Ergashev, R. et al. Technology of water supply to water inlets of pumping stations. IOP Conf. Ser. Mater. Sci. Eng. 1030, 012156 (2021).

15. Eshev, S. et al. Dynamically stable sections of large soil canals taking into account wind waves. IOP Conf. Ser. Mater. Sci. Eng. 1030, 012134 (2021).

16. Glovatsky, O., Ergashev, R., Nasirova, N., Kholbutaev, B. \& Khusanbayeva, K. Estimation of the forecast of pump ready rate for reclamation systems. IOP Conf. Ser. Mater. Sci. Eng. 1030, 012115 (2021).

17. Krutov, A., Choriev, R., Norkulov, B., Mavlyanova, D. \& Shomurodov, A. Mathematical modelling of bottom deformations in the kinematic wave approximation. IOP Conf. Ser. Mater. Sci. Eng. 1030, 012147 (2021).

18. Krutov, A., Norkulov, B., Uljaev, F. \& Jamalov, F. Results of a numerical study of currents in the vicinity of a damless water intake. IOP Conf. Ser. Mater. Sci. Eng. 1030, 012121 (2021).

19. Matyakubov, B., Begmatov, I., Raimova, I. \& Teplova, G. Factors for the efficient use of water distribution facilities. IOP Conf. Ser. Mater. Sci. Eng. 883, 012025 (2020).

20. Shaazizov, F. Studies of turbulent flow characteristics of dividing open water streams. IOP Conf. Ser. Mater. Sci. Eng. 1030, 012141 (2021).

21. Shaazizov, F., Shukurov, D. \& Shukurov, E. System for ensuring the detection and elimination of fires in the building of the hydroelectric power station. IOP Conf. Ser. Mater. Sci. Eng. 1030, 012142 (2021).

22. Uralov, B., Choriev, R. \& Maksudova, L. Substantiation of the influence of the channel shape and the roughness of machine canals on the pressure loss of irrigation pumping stations Substantiation of the influence of the channel shape and the roughness of machine canals on the pressure loss of i. (2021) doi:10.1088/1757$899 \mathrm{X} / 1030 / 1 / 012148$.

23. Uralov, B., Rakhmatov, N., Khidirov, S. \& Safarov, G. Hydraulic modes of damless water intake. (2021) doi:10.1088/1757-899X/1030/1/012123.

24. Urishev, B., Artikbekova, F., Kuvvatov, D., Nosirov, F. \& Kuvatov, U. Trajectory of sediment deposition at the bottom of water intake structures of pumping stations. IOP Conf. Ser. Mater. Sci. Eng. 1030, 012137 (2021).

25. Anghesom A. Ghebrehiwot, Kozlov D.V. Spatial and Statistical Variability Analyses of Satellite-Based Climatic Data in Mereb-Gash Basin, Water Resources, 48(1), pp. 
146-157, (2021)

26. Bednaruk S.E., Chukanov V.V., Klenov E.M., Kozlov D.V. Accounting for the Thermal State of the Sayano-Shushenskaya Dam to Determine the Safe Maximum Water Levels in the Reservoir in Developing Its Dispatch Schedules, Power Technology and Engineering, 54(4), pp. 451-455, (2020)

27. Kozlov D., Yurchenko A. The role of inspection of hydraulic structures in the assessment of their technical condition, IOP Conference Series: Materials Science and Engineering, 883(1), 012049, (2020)

28. Kozlov D., Ghebrehiwot A. Integrated design and construction approach to hydrotechnical structures in Eritrea, IOP Conference Series: Materials Science and Engineering, 869(7), 072012, (2020)

29. Kozlov D.V., Kuleshov S.L. Multidimensional Data Analysis in the Assessment of Ice-Jam Formation in River Basins, Water Resources, 46(2), pp. 152-159, (2019) 